\title{
New Challenges in Water Systems
}

\author{
Helena M. Ramos ${ }^{1, *\left(\mathbb{D}, \text { Armando Carravetta }^{2} \mathbb{D} \text { and Aonghus Mc Nabola }\right.}{ }^{3}$ (D) \\ 1 Department of Civil Engineering and Architecture, CERIS, Instituto Superior Técnico, University of Lisbon, \\ 1049-001 Lisbon, Portugal \\ 2 Department of Civil, Architecture and Environmental Engineering, University Federico II of Naples, \\ 80125 Naples, Italy; armando.carravetta@unina.it \\ 3 Department of Civil, Structural and Environmental Engineering, Trinity College Dublin, \\ D02 PN40 Dublin, Ireland; amcnabol@tcd.ie \\ * Correspondence: helena.ramos@tecnico.ulisboa.pt or hramos.ist@gmail.com
}

Received: 13 August 2020; Accepted: 18 August 2020; Published: 20 August 2020

\begin{abstract}
New challenges in water systems include different approaches from analysis of failures and risk assessment to system efficiency improvements and new innovative designs. In water distribution networks (WDNs), the risk function is a measure of its vulnerability level and security loss. Analyses of transient flows which are associated with the most dangerous operating conditions, are compulsory to grant the system liability both in water quantity, quality, and management. Specific equipment, such as air valves are used in pressurized water pipes to manage the air inside associated with the filling process, that can also act as a control mechanism, where the major limitation is its reliability. Advanced tools are developed specifically to smart water grids implementation and operation. The water system efficiency and water-energy nexus, through the implementation of suitable, pressure control and energy recovery devices, and pumped-storage hydropower solutions, provide guidelines for the determination of the most technical cost-effective result. Integrated analysis of water and energy allows more reliable, flexible, and sustainable eco-design projects, reaching better resilience systems through new concepts. The development of model simulations, based on hydraulic simulators and computational fluid dynamics (CFD), conjugating with field or experimental tests, supported by advanced smart equipment, allow the control, identification, and anticipation of complex events necessary to maintain the water system security and efficiency.
\end{abstract}

Keywords: safety and control; hydraulic transients and CFD analyses; water systems efficiency; smart water grids; water-energy nexus; energy recovery; new design solutions and eco-design

\section{Introduction}

In recent years, the lifespan of several water systems has been exceeded, so there are certain sectors from the water industry which includes drinking, storm, waste, irrigation, process industry systems, that do not reach enough operating conditions, in particular in drinking systems. This problem could produce the formation of biofilm on pipe walls [1,2], promoting bacterial growth and its transport until consumption. On the other hand, the system's own useful life, the intermittency in the supply, the leaks level, and the demands behavior cause a great variety of residence times of the drinking water and variations in the reaction of the disinfectant in the networks $[3,4]$. Chlorine disinfection is one of the principal factors in drinking water treatment processes, since it is used mainly to ensure the destruction of pathogen organisms that could be present in water.

Additionally, for efficient operation of water systems, suitable designs are required, which should consider economic criteria [5-8], hydraulic parameters, such as resilience [9] and water quality [10], and management criteria, such as system flexibility [11] and robustness [12]. However, a design is made based on a specific model of the water distribution network (WDN), and uncertainties in roughness [13] 
and mainly in future demands [14] can affect its real operating conditions. Taking into account all of these variables and uncertainties, multi-objective approaches can reveal as an alternative to reach feasible designs [15-21]. However, in water systems, cost and reliability are conflicting parameters, i.e., to improve one of them, the other has to be impaired.

Another main problem related to the operation and priming of water distribution systems is the presence of air inside the pipes [22]. There are many causes giving rise to the presence of air pockets: filling and emptying operations, temporary interruptions of water supply, vortexes in pumping feed tanks, air inlet in points with negative pressure, inflow in air valves during the negative pressure wave of a hydraulic transient and the release of the dissolved air in the water. The presence and movement of the air in water distribution pipes causes problems in most cases. Air pockets inside pipes can generate disturbances, such as the reduction of pipe cross section, even blocks, the generation of an additional head loss, which increases energy consumption of pumping groups. The decrease of pump performance is another problem, with the loss of efficiency, appearance of noise and vibration problems, corrosion inside pipelines, and significant errors in flow meters or other instrumentation equipment $[23,24]$. These problems may also lead to an irregular system operation and extreme surge pressure caused by entrapped air pockets.

Worldwide, water companies in all water sectors use smart equipment, such as some types of flowmeters to measure and at the same time control leakages, excess of pressure, and the amount of water consumed. This and other equipment are quite vital for smart management since improvements are made in the acquisition, storage, and treatment of data collected that also influences several water systems' performance indicators regarding water and energy balances $[25,26]$. The increasing need for energy in current societies is inducing more emissions of carbon dioxide to the atmosphere worsening the climate change issues. For that reason, the use of renewable energies has received excellent acceptance in recent years towards the carbon neutralization, inducing the increase of several innovative solutions [27-29]. Ensuring a clean environment and sustainable development, renewable energy sources are widely and globally appointed as future targets with great interests in hydro, wind, and solar as main green energy sources, where hydropower is considered as one of the most flexible solution for the integration of other renewables. Therefore, the idea of power production using water based on its available flow energy can contribute to the reduction of significant environmental impacts $[28,29]$.

This Special Issue comprises papers focused on the most important issues related with new challenges of water systems, such as:

- Safety and surge or disturbances control in water systems, presenting a summary of their most recent work on research, in advanced tools, with integrated methodologies, in managing assessment, new applications, modelling, and experimental test results towards more sustainable water systems, in any type of the water sector.

- Integrated analyses evidence the new challenges in hydraulic operation and computational fluid dynamics (CFD) simulations, which are increasingly expected to develop in the near future, with interesting lessons to learn and share in the definition of operating rules, types of maneuvers, and categorization of each system response.

- Another subject is regarding the water systems' efficiency, with case studies as examples of how it needs to get better results since water and energy efficiency are interconnected and are main variables in the water sector, since, in many cases, water uses energy to be supplied and energy uses water to be produced.

- A new issue is associated with smart water grids, which are linked to the former ones too, in a holistic point of view with suggestions on how to make each system smarter and more proficient.

- The urgency of new challenges related to water-energy nexus and energy recovery in this new era for sustainable and eco-design solutions, due to restrictions imposed by climate change, calls for more flexible and new adaptive answers. 
Hence, the following section summarizes the contributions according to this categorization.

\section{Contributed Papers}

\subsection{Safety and Control}

Several trends of safety research can be identified, such as risk analysis, where assessment models form the basis for building decision models, where the assessment of design options in terms of technical safety issues, is the basis for choosing the best result. The loss of safety in water systems may result directly from the failure of its individual subsystems or elements, such as water intakes, pumping stations, the water distribution network (WDN) or its utilities; from the failure of other technical systems (e.g., sewerage, energy, water structures); from undesirable extreme natural phenomena like floods and droughts; from the incidental pollution of water sources. Risk analysis of water systems should be preceded by analysis of the reliability of all subsystems in terms of interruptions to water supply, as well as failure to meet quality requirements for health posing threats to consumers of water.

Risk acceptance criteria can be used in the decision-making process regarding the operation of such a system. These criteria are related to the reliability of the system operation, in terms of both quantity and quality, in accordance with applicable rules, as well as social and economic conditions. A proposed Modified Multi-Criteria Decision Analysis Implementing an Analytic Hierarchy Process for Risk Assessment as regards failures in a WDN is presented. This procedure entails a choice of criteria influencing the risk of failure in a WDN, and the future occurrence thereof. Another important step in the procedure overall is the selection of relevant alternatives and the determination of implications in the defined criteria. Several categories and subcategories of criteria for the analysis and identification of areas at risk of WDN failure can be identified based on design, performance, operation, social impacts, financial losses, environmental, and surrounding impacts.

The water quality needs to verify the fluid interaction between disinfectant and contaminant that can occur along WDN which is dominated by convection, analyzing the variation of Turbulent Schmidt Number vs. experimental tests. More accurate mixing models improve the water quality simulations to have an appropriate control for chlorine and possible contaminants in water systems.

On the other hand, air inside a pressurized flow requires careful operational attention to understand its behavior (Figure 1), because characteristic curves of the ratio between the admitted/ejected airflow and the difference in pressure between the inside and outside of an air valve obtained with experimental tests in all possible operating regions (Figure 1) are not always known correctly.

Unfortunately, the available conditions under air valves are nearly impossible to reproduce in lab conditions with sufficient reliability. The use of CFD models can be used, not only to analyze specific hydraulic elements in water systems, but also to verify the source of flow problems, assessing the hypotheses drawn by operator experts, and to identify inconsistences regarding flow measurements in real hydraulic circuits. Intensive studies stated that several errors are mostly associated to flowmeters, and the low accuracy is connected to the perturbations induced by air and the system layout. 


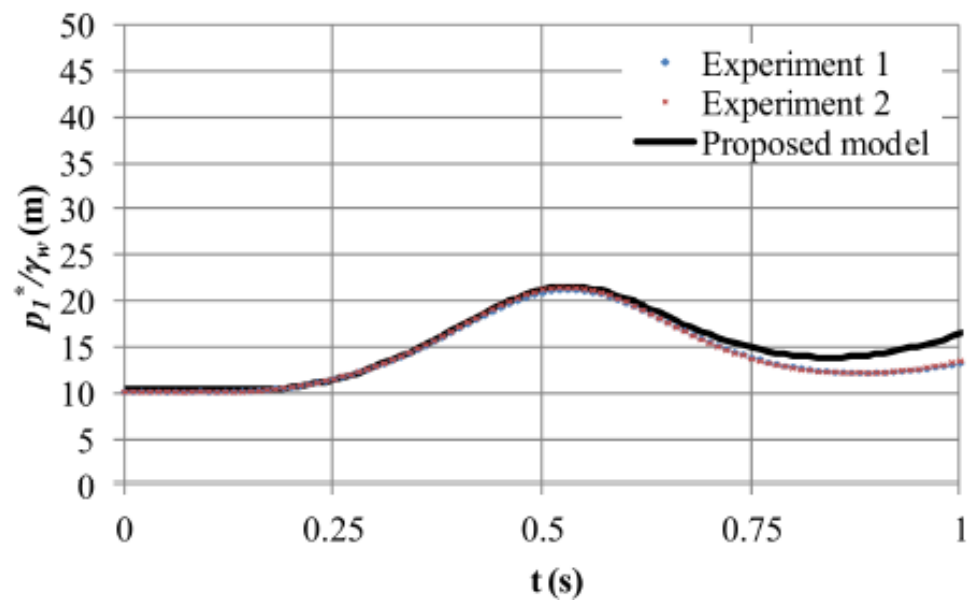

(a)

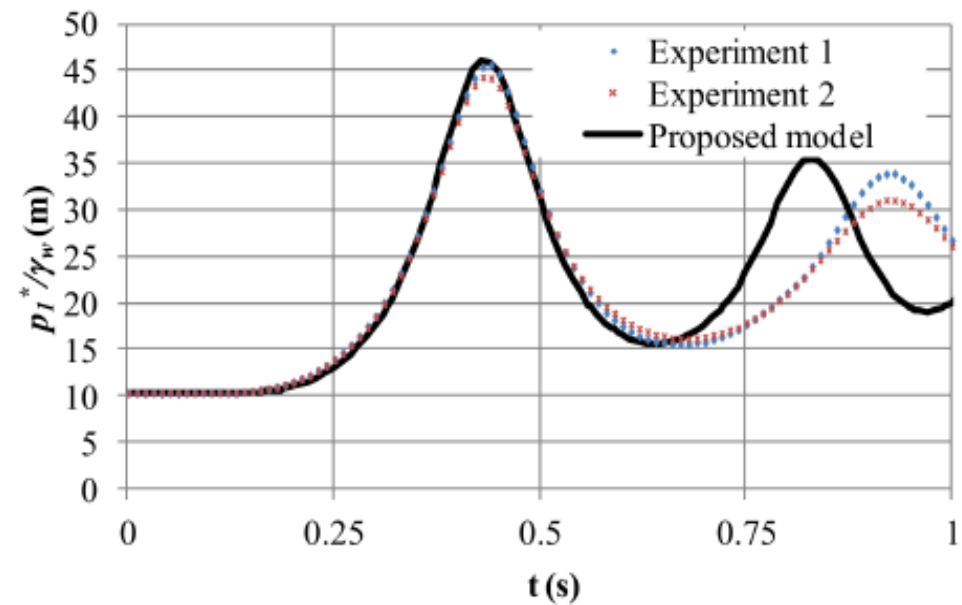

(b)

Figure 1. Air pocket pressure patterns: for initial air pocket sizes $(\mathrm{x} 0) 1.36 \mathrm{~m}$, and initial gauge pressures (p0) of 0.50 (a) and 1.25 (b) bar in the hydro-pneumatic tank during a filling process.

\subsection{Hydraulic Transients and CFD Analyses}

A measurement of the resilience is the capacity to meet demands during emergency situations when pipe bursts can occur. An emitter coefficient is added to each node to simulate a leak flow that is caused by a pipe burst percentage of the total inflow. The behavior of resilience, according to the size of the main pipe system and the node where the pipe burst occurred can be identified. In a WDN pipes that are far from the feed reservoirs have smaller diameters and their flows are very low. On the other hand, pipes close to the reservoir are well sized, and have enough capacity to support demand variation. Finally, it is noticeable that for big diameters, resilience is less affected by a pipe burst. This can be confirmed when comparing Figure 2a, where the pressure zones for the highest consumption period are shown for the initial scenario, and with big diameters trunk network of $20 \%$ and $60 \%$ of the pipes, even with leakage. The rehabilitation significantly increases the pressure in the entire network. In addition, when the pipe burst is simulated, the pressure drop is reduced but the minimum value needs to be kept. The flow behavior inside the pipe system can induce some measurement uncertainties, usually taken for granted, that can be identified using advanced analyses based on hydraulic models and CFD simulations (Figure 2b). 

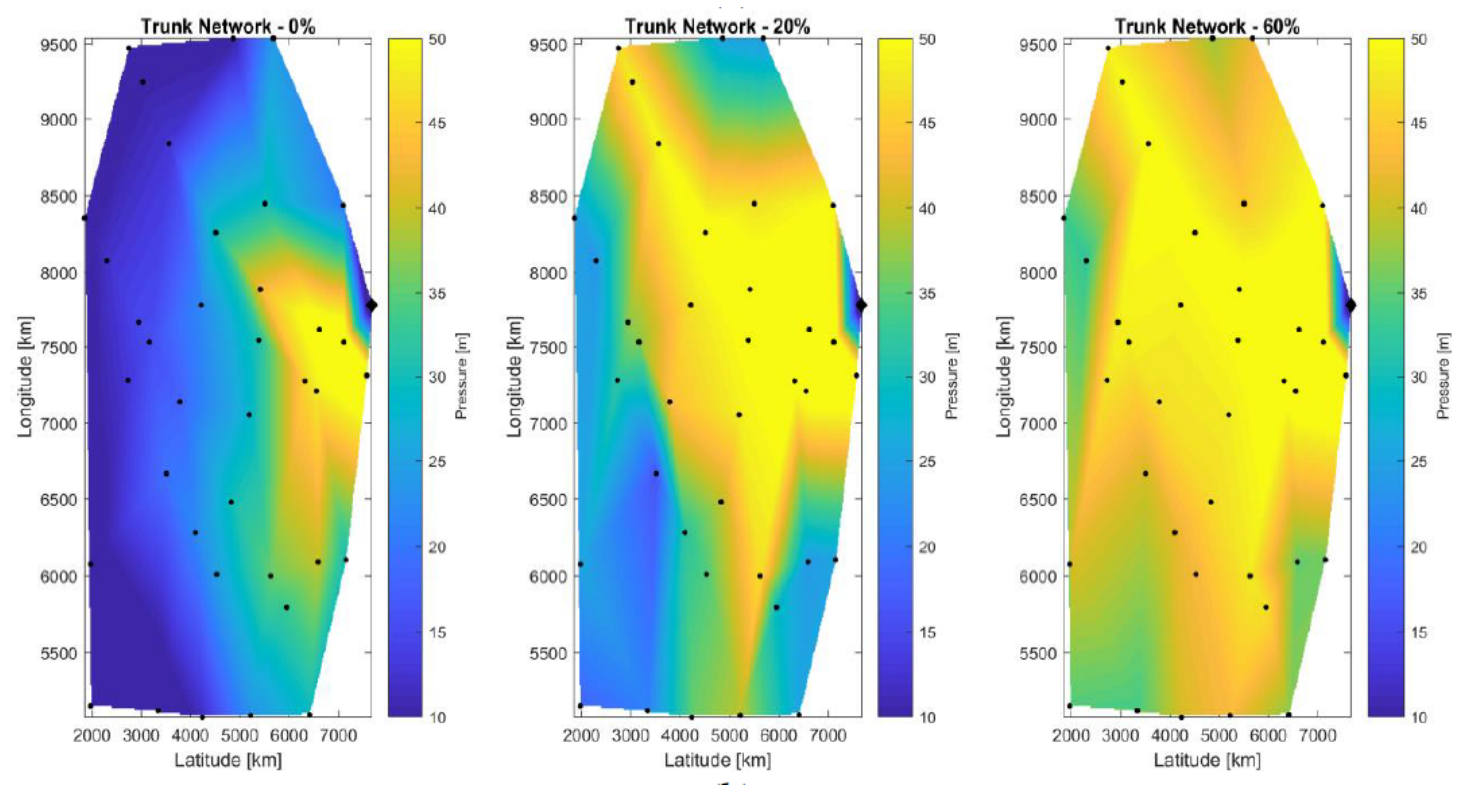

(a)
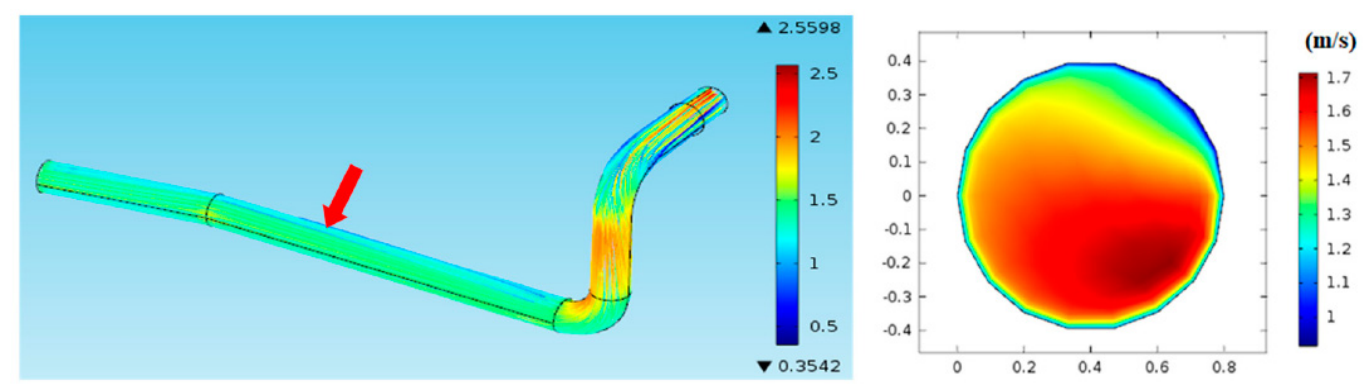

(b)

Figure 2. Pressure zones for the initial scenario and for trunk mains with $20 \%$ and $60 \%$ of the pipes with bigger diameters and a pipe burst (a); and streamlines and velocity distribution in the cross section of a pipe (b).

\subsection{Water Systems Efficiency}

The flow measurements can be correlated to the system efficiency. Usually, the systems are in part driven by gravity and by pressure differences, which require a pumping station. If the measurement accuracy is guaranteed (Figure 3), a higher energy efficiency level is possible to achieve, making possible a working period plan in the lower energy tariffs depending on the regularization ability and the water needs downstream.

Pressure reducing valves (PRVs) are a convenient device for reducing leakage by pressure control. However, the energy dissipation that takes place in a PRV is wasteful of energy resources, and this energy could be recovered by substituting or putting in series, the PRV with a micro-turbine. Thus, in addition to the reduction of water losses, a certain part of the energy in the network could be recovered, reducing greenhouse gas emissions and making the water supply system more sustainable [14]. Due to the potential of hydropower in these systems, several investigations have focused on the evaluation of the installation of these devices in water networks, showing that up to $40 \%$ of the gross power potential available in a PRV could be recovered by replacing/coupling the PRV by/with a PAT, depending on the manager objectives. 
Some case studies presented show results achieved about the implementation of measures for the monitoring and water loss control, which allowed accessing a higher level of efficiency, especially in the reduction of water losses, in saving energy, and the consequent reduction of associated costs.
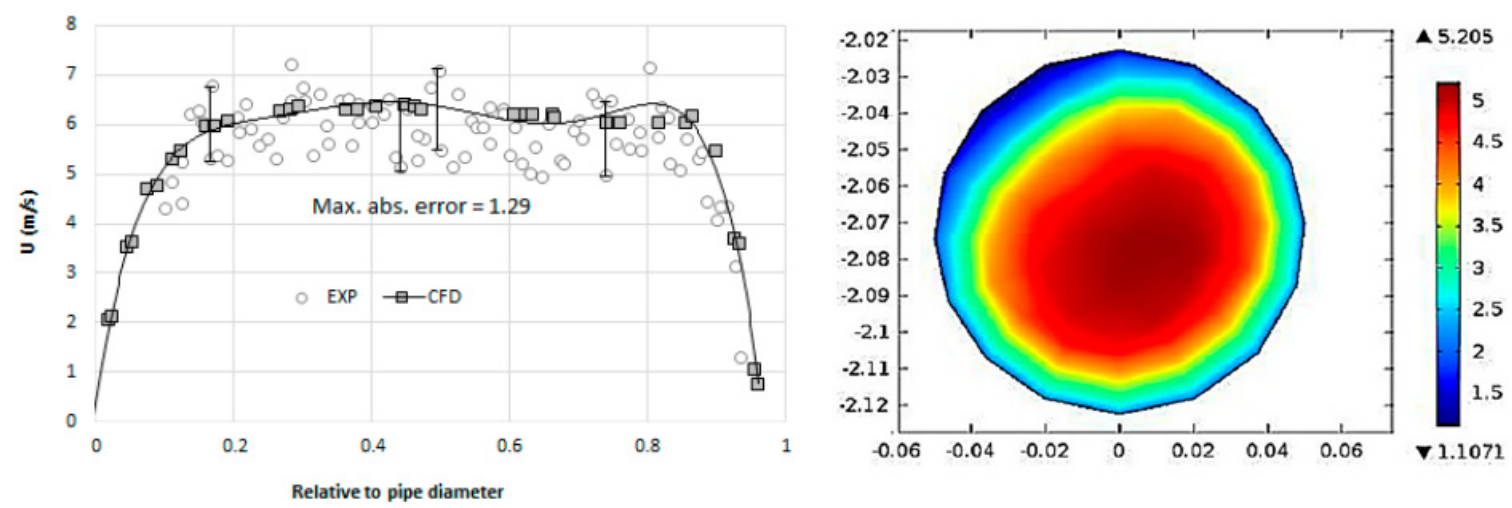

Figure 3. Flow velocity distribution and implications on the system balance efficiency.

\subsection{Smart Water Grids}

Water management towards smart grids and cities is an issue increasingly appreciated under financial and environmental sustainability focus in any water sector, disclosing the technological breakthroughs associated with water and energy use. The water industry is subject to new challenges regarding the sustainable management of urban water systems (Figure 4). There are many external factors, including impacts of climate change, drought, and population growth in urban centers, which lead to an increase of the responsibility, in order to adopt more sustainable management of the water sector. Smart water management aims at the exploitation of water, at the regional or city level, on the basis of sustainability and self-sufficiency. This exploitation is carried out through the use of innovative technologies, such as information, control technologies, and monitoring.

The development of smart techniques requires technology use in water systems, as well as its implementations. They will improve the performance of many networks characterized by degraded infrastructure, irregular supplies, and low levels of customer satisfaction or substantial deviations of the proportional bills to real consumption. A smart water system can lead to more sustainable water services, allowing to reduce financial losses, enabling innovative business models to serve better the urban and rural populations. 


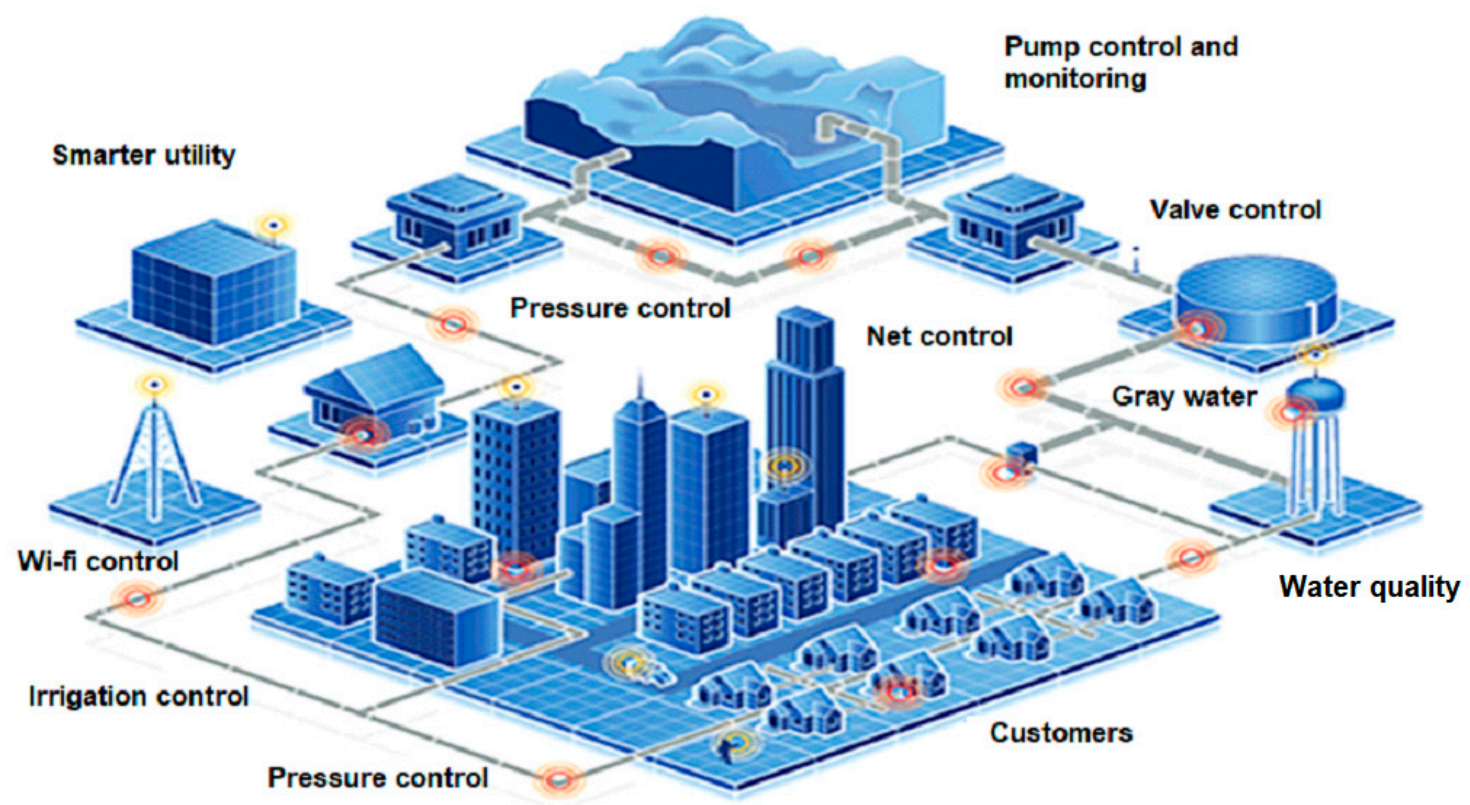

(a)

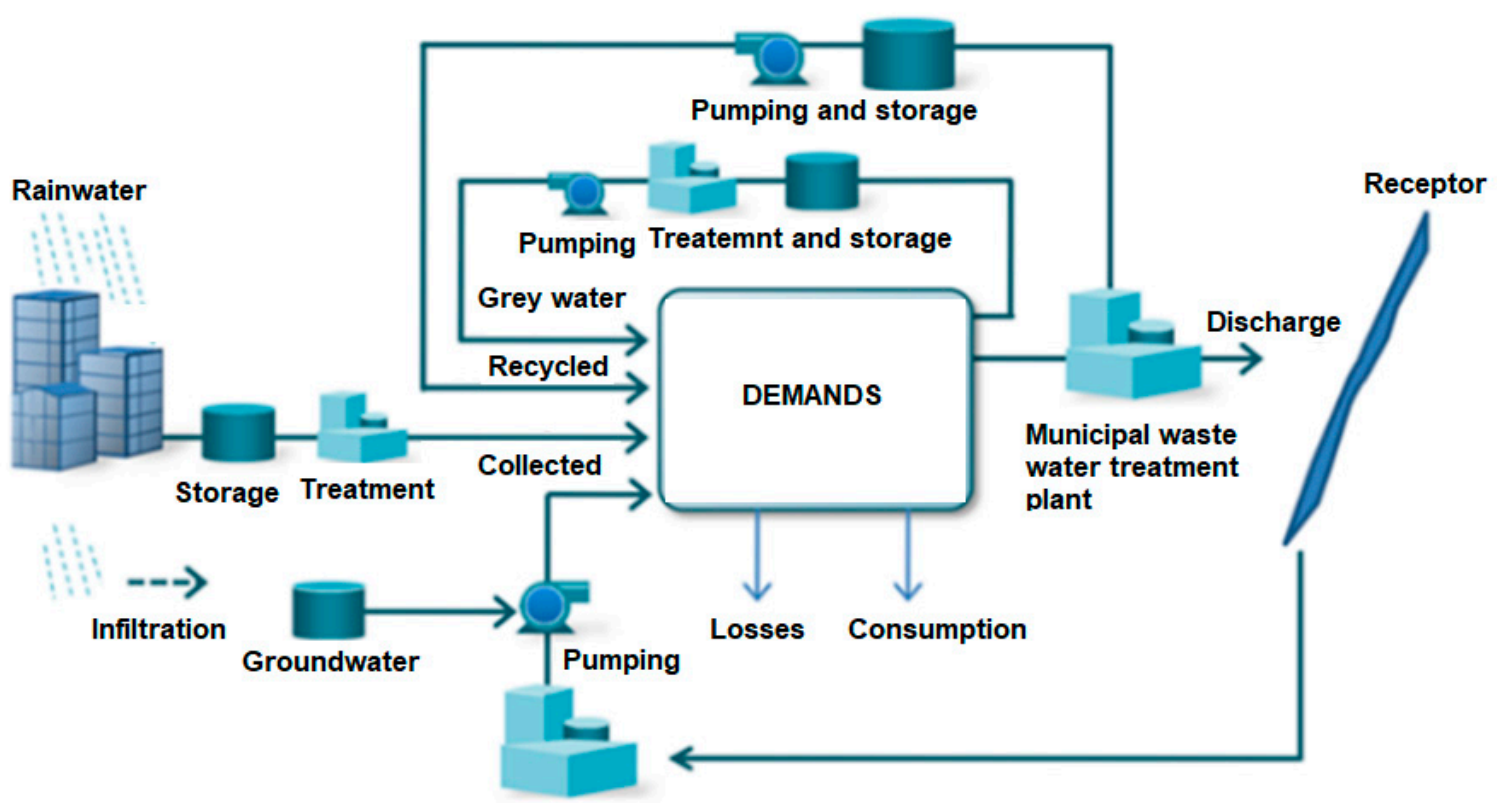

(b)

Figure 4. Holistic view of smart grids: integration of components in a smart water grid in urban environment (a); and water cycle process in a smart water grid (b).

\subsection{Water-Energy Nexus}

Water abstraction and distribution are among the activities in which the water-energy nexus plays an important role. In the European Union, as an example, $8 \%$ of the total energy consumption, in recent years, was related to the water supply. In addition, it is estimated that 32 billion cubic meters per year (66\% of the treated water) are lost in the water distribution process globally. This is mainly due to the ageing infrastructure, the non-optimal design of the water supply systems, and the increase in water stress, in urban areas. Different strategies have been proposed to reduce energy consumption from fossil fuels in the water industry sector, by using renewable energy sources, available flow energy, 
or by recovering the excess of heat at the wastewater treatment plant. Leakage management can also play a major role in the reduction of energy consumption in the water sector. Thus, pressure control in water distribution networks is one of the most effective measures to reduce leakages, because of the direct relation between pressure and leakage rate. Hence, Pressure Reducing Valves (PRVs) can reduce water losses by pressure control. The energy dissipation that takes place in a PRV is wasteful of energy resources, and this energy could be recovered by substituting the PRV with a micro-hydro device. Thus, in addition to the reduction of water losses, a certain part of the energy in the network could be recovered, reducing greenhouse gas emissions, the water footprint, and making the water supply systems more sustainable. Due to the potential of hydropower in these systems, several investigations have focused on the evaluation of the installation of these devices in water networks, showing that up to around half of the gross power potential available in a PRV could be recovered by replacing the PRV with a PAT (Figure 5). Other potential locations for installing hydropower turbines are in break pressure tanks, water storages, or water treatment plants, allowing the estimation of significant energy generation potential in some locations of water systems.

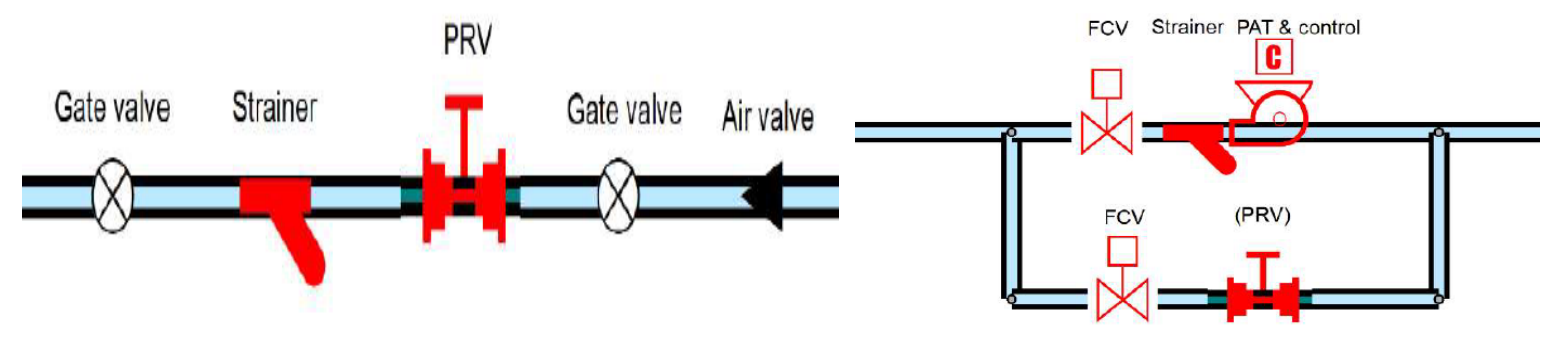

(a)

(b)

Figure 5. Installation scheme of a pressure reducing valve (PRV) (a) and a pump as turbine (PAT) (b).

\subsection{Energy Recovery}

A particular class of micro-turbines consists of pumps working in reverse mode, i.e., pump as turbines (PAT). These are devices that can be installed along distribution pipes to reduce pressure at nodes and recover energy, with significantly reduced investment costs compared to traditional turbines. PATs are considered to be a cheaper technology compared to traditional turbines for small hydropower energy recovery. However, information related to the total PAT cost, also including installation cost, is not easily accessible. Overall, methodologies focused on the use of PATs took into account a PAT cost according to the generated power. For some analyzed cases, the replacement of PRVs with PATs would involve powers between $400 \mathrm{~W}$ and $2 \mathrm{~kW}$ and when the PAT cost was considered between $50 \%$ and $10 \%$ of the total costs, showed a payback period between 3 and 6 years, respectively (Figure 6). 


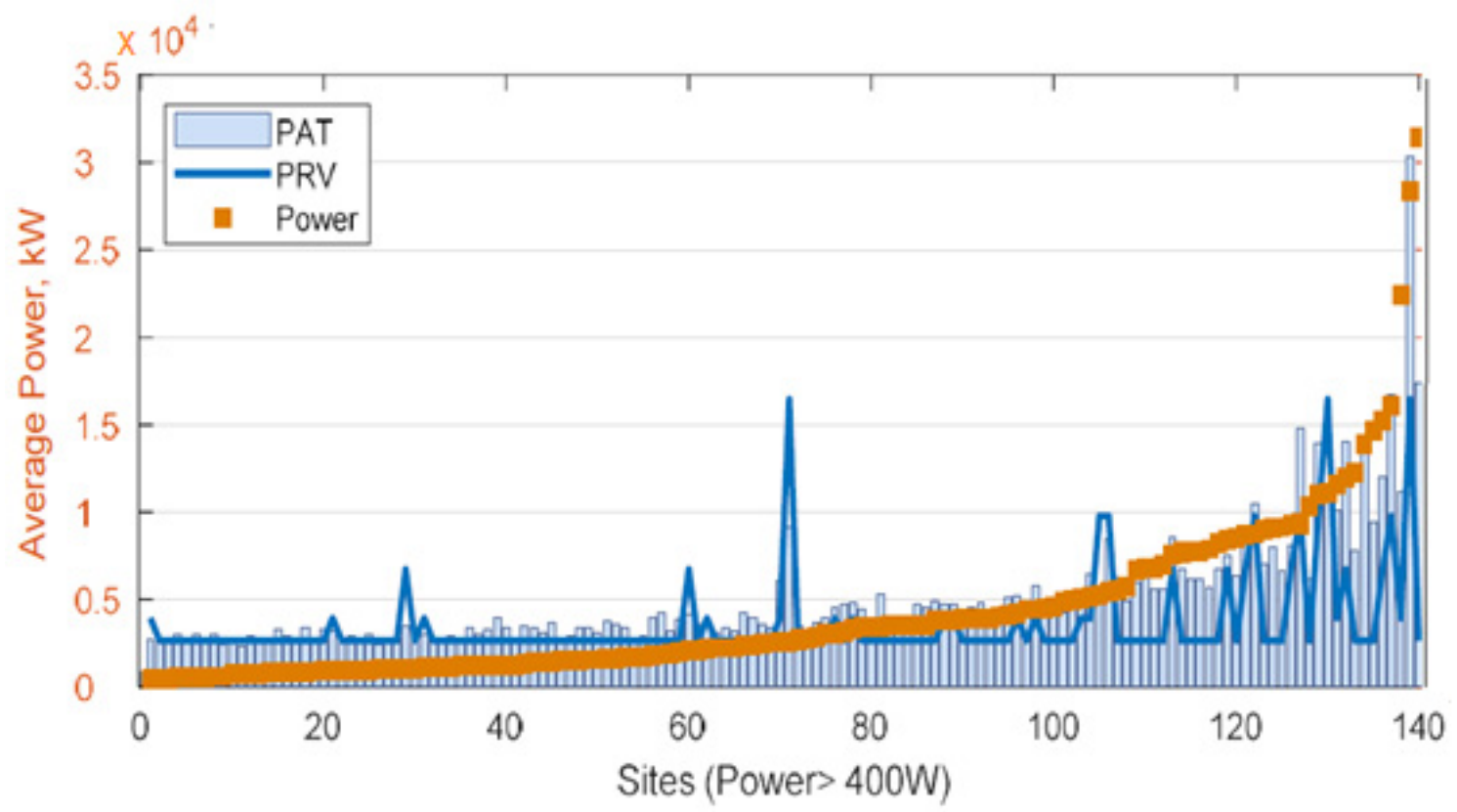

Figure 6. Micro-hydro average generated power by PATs (red) and comparison between PAT vs. PRV total cost (blue).

\subsection{New Design Solutions and Eco-Design}

Energy and climate change are thoroughly linked, since fossil energy generation highly affects the environment, and climate change influences the renewable energy generation capacity. There are studies that give a new contribution to the energy generation in water infrastructures by means of new concept installations, in particular an inline pumped-storage hydro (IPSH) solution. Increasingly, there are great interests in wind and solar as green energy sources, and hydropower is seen as a huge flexibility. Currently, hydropower is considered as one of the most preferred sources to produce electricity and, simultaneously, for integration of other renewable sources.

It is worth mentioning that the pump consumes energy and the hydropower produces it creating a new loop system adapted to existing infrastructures with direct flow condition, based on the available head, a by-pass line, that can be activated to use the head difference for energy generation.

Therefore, the idea of power production using water based on its available flow energy can contribute to the reduction in significant environmental impacts (Figure 7). The application of MHP solutions has gone even further to different water sectors, e.g., irrigation networks with a promising future of their applicability. Additionally, novel solutions using the compressibility effect of air have been presented in some studies that can be combined with pumped-storage hydropower (PSH and ACUR) to offer a hybrid solution. 


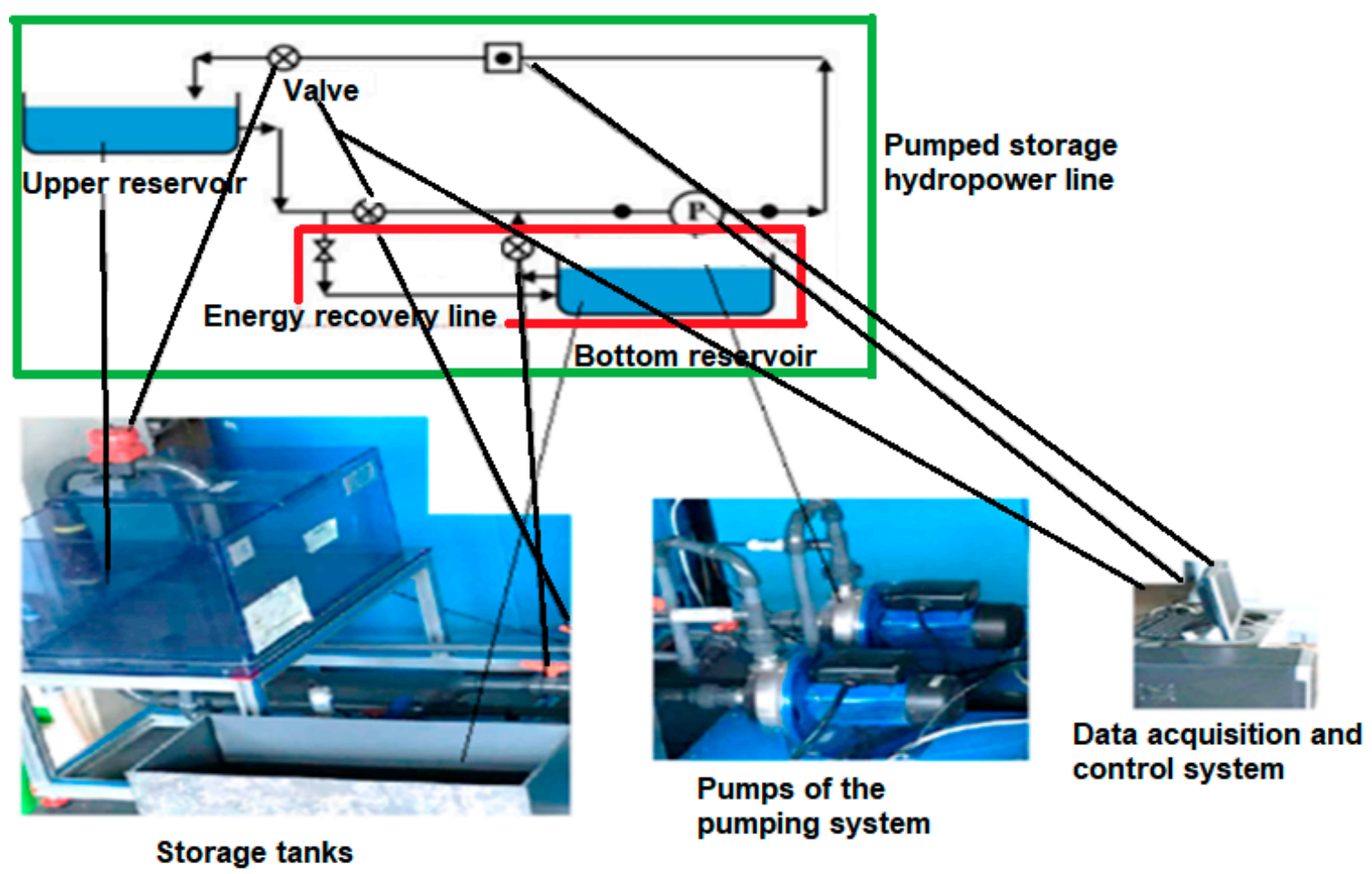

(a)

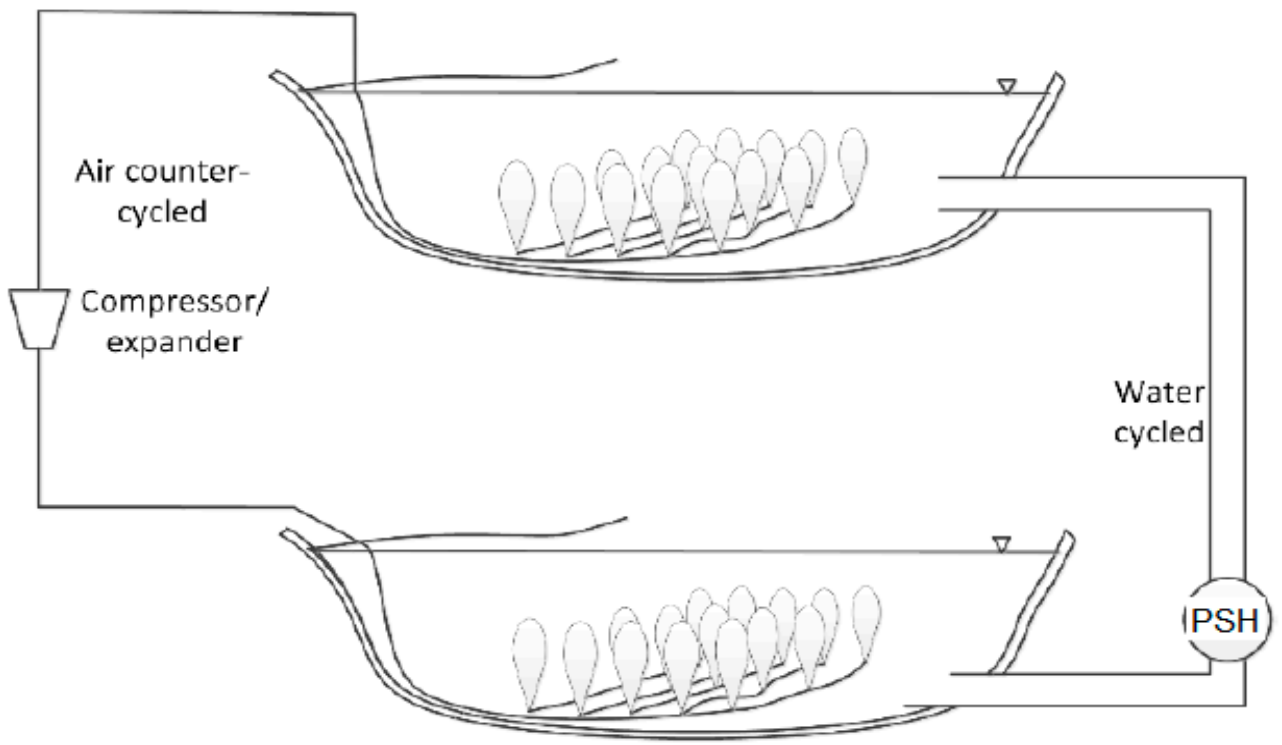

(b)

Figure 7. Pumped-storage hydropower integration in water systems (a) and with an Air Cushion Underground Cavern (ACUR) (b).

\section{Conclusions}

Risk analysis is found to contribute significantly to the reduction of failure overall, identifying and limiting their causes and effects. If numerous overall failures arise in a water distribution network (WDN), the water company has to modernize and renovate the system, so as to minimize leakages, bursts, and other pipeline failures. A database of weak points of system functioning, with 
particular emphasis placed on the frequency of occurrences and associated negative effects, need to be registered. In safety management, the selection of risk protection measures and its implementation into operational practice needs to be carried out for the effectiveness of applied solutions. Residence Time Distribution (RTD) curves are good features and a novel proposal on mixing cross-junctions, in order to calibrate simulation processes of water quality analysis, with the help of stimulus-response techniques. Finding solutions to the problem of inadequate use of chlorine is an issue that involves various aspects. When WDN presents a high degree of reaction due to pipe conditions and residence times, concentrations in some areas decrease rapidly and can affect costumer health.

In addition, a system that is capable of operating only with minimum pressure values is not sufficiently robust to surpass emergency situations, such as pipe bursts or firefighting, causing water shortage in some areas. To avoid this problem, the resilience is an important parameter to be considered, since it reflects the network capacity to cope with a variety of events. The methodology explicitly quantifies the benefit of resilience through an energy recovery solution. During normal operation, pumps as turbines (PATs) operate to perform pressure control, while, in emergency scenarios, the flow can be driven through a by-pass to regulate pressure at critical points. For existing networks, the rehabilitation only of the main pipes is an alternative to improve resilience, since these pipes are the most relevant for the system.

CFD techniques provide a tool for determining in detail the behavioral characteristics of hydraulic elements. However, CFD requires a proper calibration of the models, so it will be essential to validate the results by tests in field or laboratory. Specifically, the effectiveness of these techniques to represent the behavior of air valves, bends, cross sections, pumps, turbines, and other hydraulic elements that are installed in water systems are analyzed.

In some cases, the measurement problem has a significant influence on the correct management of technical, hydraulic, and economic efficiency of water companies. Since the hydraulic circuits have, normally, flowmeters, a water balance is necessary. These balances are important tools to detect leaks throughout the supply and distribution processes by assessing that the installation requirements proposed by manufactures are not sufficient to dissipate such detected uncertainties.

Regarding the excess of pressure in water systems, the replacement or conjunction of PRVs with PATs as a measure to generate energy and reduce leakage represents an efficient strategy to improve the sustainability of water systems. This is a challenge to control pressure and generate energy at the same time, also analyzing the most convenient element from technical and economic points of view, highlighting the potential of micro hydro power (MHP) installations in general and PATs in particular, as a tool to reduce electricity costs and improve the sustainability of water systems.

Some of the main advantages of smart water management are a better understanding of the water system, namely the detection of leaks, conservation and monitoring of water quality. The implementation of smart water system technologies enables public service companies to build a complete database for the identification of the areas where water losses or illegal connections occur. The advantages of smart water grids are economic benefits to water and energy conservation, while the efficiency of the system can improve customers service. Some of the main smart technologies are listed as follows: (i) smart pipe and sensor; (ii) smart water metering; (iii) Geographic Information System (GIS); (iv) cloud computing and supervisory control and data acquisition; (v) models, tools of optimization, and decision support systems.

The contributors to this Special Issue are invited to provide a series of approaches to create innovation, practical implementation, and further awareness and solutions by presenting research based on case studies with integrated approaches, advanced tools, and water management practices, which allow to enhance:

1. Innovative water network analyses, safety solutions, and available tools, through specific studies in new or existing water infrastructures of small to big scales. This does not require significant changes and bulky investments to increase their efficiency, flexibility, resilience, robustness, and feasibility; 
2. The energy generation using the gravitational flow appears as a significant decentralized economic advantage in the definition of the energy recovery solutions;

3. Depending on the type of demand, the applications show smart pressure and flow control measures for new challenges in future water systems including water-energy efficiency solutions;

4. The smart approach based on a controlled water and consequently energy recovery solution, increases water systems flexibility, contributing to smart management and water and energy efficiency in the water sector. These procedures allow to better face the existing costs associated with pumping, treatment plants, water leakage, expansion and reparation of infrastructures, and water bills for customers.

Author Contributions: H.M.R. conceived and led the development of this Special Issue and this paper; A.C. and A.M.N. contributed substantially to the writing. All authors have read and agreed to the published version of the manuscript.

Funding: This research received no external funding.

Acknowledgments: The authors of this paper, who served as guest editors of this Special Issue, wish to thank the journal editors, all authors submitting papers to this Special Issue, and the many referees who contributed to paper revision and improvement of all published papers.

Conflicts of Interest: The authors declare no conflict of interest.

\section{Acronyms}

$\begin{array}{ll}\text { ACUR } & \text { Air Cushion Underground Cavern } \\ \text { CFD } & \text { computational fluid dynamics } \\ \text { GIS } & \text { geographic Information System } \\ \text { IPSH } & \text { inline pumped-storage hydro } \\ \text { MHP } & \text { Micro-hydropower } \\ \text { PAT } & \text { Pump as turbine } \\ \text { PRV } & \text { Pressure reducing valve } \\ \text { PSH } & \text { Pumped-storage hydropower } \\ \text { WDN } & \text { Water distribution network } \\ \text { WSS } & \text { Water supply system }\end{array}$

\section{References}

1. Geem, Z.W.; Kim, J.H.; Loganathan, G. A New Heuristic Optimization Algorithm: Harmony Search. Simulation 2001, 76, 60-68. [CrossRef]

2. Maier, H.R.; Simpson, A.R.; Zecchin, A.C.; Foong, W.K.; Phang, K.Y.; Seah, H.Y.; Tan, C.L. Ant Colony Optimization for Design of Water Distribution Systems. J. Water Resour. Plan. Manag. 2003, 129, 200-209. [CrossRef]

3. Suribabu, C.R.; Neelakantan, T.R.; Renganathan, N.T. Design of water distribution networks using particle swarm optimization. Urban. Water J. 2006, 3, 111-120. [CrossRef]

4. Baños, R.; Reca, J.; Martínez, J.; Gil, C.; Márquez, A.L.; Gil, C. Resilience Indexes for Water Distribution Network Design: A Performance Analysis Under Demand Uncertainty. Water Resour. Manag. 2011, 25, 2351-2366. [CrossRef]

5. Shokoohi, M.; Tabesh, M.; Nazif, S.; Dini, M. Water Quality Based Multi-objective Optimal Design of Water Distribution Systems. Water Resour. Manag. 2016, 31, 93-108. [CrossRef]

6. Marques, J.; Cunha, M.D.C.; Savić, D. Using Real Options in the Optimal Design of Water Distribution Networks. J. Water Resour. Plan. Manag. 2015, 141, 04014052. [CrossRef]

7. Schwartz, R.; Housh, M.; Ostfeld, A. Least-Cost Robust Design Optimization of Water Distribution Systems under Multiple Loading. J. Water Resour. Plan. Manag. 2016, 142, 04016031. [CrossRef]

8. Giustolisi, O.; Laucelli, D.; Colombo, A.F. Deterministic versus Stochastic Design of Water Distribution Networks. J. Water Resour. Plan. Manag. 2009, 135, 117-127. [CrossRef]

9. Lansey, K.E.; Duan, N.; Mays, L.W.; Tung, Y. Water Distribution System Design Under Uncertainties. J. Water Resour. Plan. Manag. 1989, 115, 630-645. [CrossRef] 
10. Zheng, F.; Simpson, A.; Zecchin, A.C. Improving the efficiency of multi-objective evolutionary algorithms through decomposition: An application to water distribution network design. Environ. Model. Softw. 2015, 69, 240-252. [CrossRef]

11. Geem, Z.W. Multiobjective Optimization of Water Distribution Networks Using Fuzzy Theory and Harmony Search. Water 2015, 7, 3613-3625. [CrossRef]

12. Prasad, T.D.; Park, N.-S. Multiobjective Genetic Algorithms for Design of Water Distribution Networks. J. Water Resour. Plan. Manag. 2004, 130, 73-82. [CrossRef]

13. Ramos, H.; Borgå, Å. Pumps as turbines: An unconventional solution to energy production. Urban. Water 1999, 1, 261-263. [CrossRef]

14. Carravetta, A.; Houreh, S.D.; Ramos, H.M. Pumps as Turbines: Fundamentals and Applications, 1st ed.; Springer: Cham, Switzerland, 2017.

15. Pérez-Sánchez, M.; Sánchez-Romero, F.-J.; Ramos, H.; López-Jiménez, P.A. Energy Recovery in Existing Water Networks: Towards Greater Sustainability. Water 2017, 9, 97. [CrossRef]

16. De Marchis, M.; Freni, G. Pump as turbine implementation in a dynamic numerical model: Cost analysis for energy recovery in water distribution network. J. Hydroinformatics 2015, 17, 347-360. [CrossRef]

17. Carravetta, A.; Del Giudice, G.; Fecarotta, O.; Ramos, H. PAT Design Strategy for Energy Recovery in Water Distribution Networks by Electrical Regulation. Energies 2013, 6, 411-424. [CrossRef]

18. Lima, G.M.; Luvizotto, J.E.; Brentan, B.M.; Ramos, H. Leakage Control and Energy Recovery Using Variable Speed Pumps as Turbines. J. Water Resour. Plan. Manag. 2018, 144, 04017077. [CrossRef]

19. Carravetta, A.; Del Giudice, G.; Fecarotta, O.; Ramos, H. Energy Production in Water Distribution Networks: A PAT Design Strategy. Water Resour. Manag. 2012, 26, 3947-3959. [CrossRef]

20. Lima, G.M.; Brentan, B.M.; Izquierdo, J.; Ramos, H.; Luvizotto, J.E. Trunk Network Rehabilitation for Resilience Improvement and Energy Recovery in Water Distribution Networks. Water 2018, 10, 693. [CrossRef]

21. Pietrucha-Urbanik, K.; Tchórzewska-Cieślak, B. Approaches to Failure Risk Analysis of the Water Distribution Network with Regard to the Safety of Consumers. Water 2018, 10, 1679. [CrossRef]

22. García-Todolí, S.; Iglesias-Rey, P.L.; Mora-Meliá, D.; Martínez-Solano, F.J.; Fuertes-Miquel, V.S. Computational Determination of Air Valves Capacity Using CFD Techniques. Water 2018, 10, 1433. [CrossRef]

23. Coronado-Hernández, Ó.E.; Besharat, M.; Fuertes-Miquel, V.S.; Ramos, H. Effect of a Commercial Air Valve on the Rapid Filling of a Single Pipeline: A Numerical and Experimental Analysis. Water 2019, 11, 1814. [CrossRef]

24. Cervantes, D.H.; Delgado-Galván, X.; Nava, J.L.; López-Jiménez, P.A.; Rosales, M.; Mora-Rodriguez, J. Validation of a Computational Fluid Dynamics Model for a Novel Residence Time Distribution Analysis in Mixing at Cross-Junctions. Water 2018, 10, 733. [CrossRef]

25. Ramos, H.; McNabola, A.; López-Jiménez, P.A.; Pérez-Sánchez, M. Smart Water Management towards Future Water Sustainable Networks. Water 2019, 12, 58. [CrossRef]

26. Simão, M.; Besharat, M.; Carravetta, A.; Ramos, H. Flow Velocity Distribution Towards Flowmeter Accuracy: CFD, UDV, and Field Tests. Water 2018, 10, 1807. [CrossRef]

27. García, I.F.; Novara, D.; McNabola, A. A Model for Selecting the Most Cost-Effective Pressure Control Device for More Sustainable Water Supply Networks. Water 2019, 11, 1297. [CrossRef]

28. Storli, P.-T.; Lundström, T.S. A New Technical Concept for Water Management and Possible Uses in Future Water Systems. Water 2019, 11, 2528. [CrossRef]

29. Ramos, H.; Dadfar, A.; Besharat, M.; Adeyeye, K. Inline Pumped Storage Hydropower towards Smart and Flexible Energy Recovery in Water Networks. Water 2020, 12, 2224. [CrossRef]

(C) 2020 by the authors. Licensee MDPI, Basel, Switzerland. This article is an open access article distributed under the terms and conditions of the Creative Commons Attribution (CC BY) license (http://creativecommons.org/licenses/by/4.0/). 